\title{
Santuários e romarias na Argentina: dinâmicas sociais, políticas e culturais
}

\author{
Wiliam de Souza Martins
}

Fogelman, Patricia; Ceva, Mariela; Touris, Claudia (Ed.). El culto mariano en Luján y San Nicolás: religiosidad e historia regional. Buenos Aires: Biblos, 2013.

A recente contribuição trazida por um conjunto de estudiosos argentinos deve merecer a maior atenção da comunidade de historiadores interessada no estudo das práticas e das representaçóes religiosas. Ligando-se ao Consejo Nacional de Investigaciones Científicas y Tecnológicas (Conicet), à Universidad de Buenos Aires (UBA), à Universidad Nacional de Luján (Unlu) e a outras instituições de pesquisa, os organizadores e demais autores publicaram uma coletânea que traz a marca do trabalho coletivo de pesquisa e do esforço conjunto de reflexáo metodológica. Devido a tais características, a importância da obra vai além do estudo específico da dinâmica social e das apropriaçóes políticas construídas em torno aos santuários marianos localizados em Luján e em San Nicolás, trazendo também hipóteses e reflexóes que podem servir de ponto de partida para a análise do culto à Virgem Maria em outros contextos da ibero-américa.

$\mathrm{Na}$ introdução, de autoria das três organizadoras do volume, estão delineadas as principais diretrizes de interpretação da devoção mariana irradiada dos dois locais de peregrinação selecionados. Superando o enfoque meramente institucional, as autoras/organizadoras amparam-se em uma abordagem interdisciplinar para dar conta da complexidade dos fenômenos religiosos em foco. De acordo com tal perspectiva, a ação institucional da Igreja é apenas um elemento no interior de um conjunto mais vasto que compóe o campo religioso. Nesse, o imaginário mariano e os modelos de santidade emanados da instituição eclesiástica interagem com as identidades coletivas de romeiros, devotos e demais agentes sociais, adquirindo aqueles, a partir da referida interação, novos conteúdos e significados. Situando-se entre a história social e a cultural da religiáo, o conjunto dos estudos procura igualmente inserir-se no campo da história regional. Superando uma concepção estritamente geográfica do conceito de região, compreendido como práticas sociais inseridas no âmbito de determinado território, as pesquisadoras procuram defini-lo como "um espaço cultual e relacional”, que não é estritamente físico, econômico ou geográfico. A escala média de observação priorizada nos estudos afasta-se, como explicam as autoras, da perspectiva da microanálise, que enfatiza as tramas, as incertezas e os horizontes de expectativa de agentes individuais. A esca- 
la intermediária de observação foi escolhida como a mais adequada para: analisar a interação entre as práticas devocionais marianas produzidas em escala local e os agentes sociais que operam em cada região; compreender as estratégias políticas de construção de identidades nacionais a partir dos âmbitos local e regional; e estudar em uma perspectiva apropriada o modus operandi de uma instituição cujos agentes e doutrinas seguem diretrizes de um centro supranacional.

Os três objetivos mencionados são trabalhados nos cinco textos da coletânea que abordam, em diferentes perspectivas e temporalidades, o templo dedicado à Imaculada Concepção da Virgem Maria, em Luján, e o santuário construído em homenagem a Nossa Senhora do Rosário em San Nicolás. Seguindo uma sequência cronológica, aparece em primeiro lugar o estudo que Patricia A. Fogelman dedicou ao primeiro santuário. Em uma pesquisa minuciosa que abarca um período de dois séculos, o texto desvela diferentes estratégias sociais e políticas de construção de memórias e identidades coletivas. No primeiro plano da análise, encontra-se o padre Jorge María Salvaire, clérigo da Congregação da Missão, que em 1885 publicou em Buenos Aires a Historia de Nuestra Señora de Luján, su origen, su Santuario, su Villa, sus milagros y su culto. Em um período marcado pela forte ação secularizadora do Estado sobre a vida pública - em que aparecem medidas como a educação obrigatória e laica, a instituição do casamento civil, a ruptura de relaçóes com o Vaticano - , a obra de Salvaire está inserida na estratégia da Igreja de reagir à política de caráter libe- ral. O início da construção da Basílica Nacional de Luján, templo edificado em estilo neogótico, cuja primeira pedra foi lançada em 1887, também aparece como parte desse movimento de reação. De maneira engenhosa, a autora propóe que tanto a obra de Salvaire quanto a nova basílica podem ser compreendidas como ex-votos ofertados à Virgem em retribuição a favores alcançados pelos protagonistas de tais realizaçóes.

Analisando tanto o texto como as imagens presentes na obra de Salvaire, a autora investiga a operação seletiva de memória conduzida pelo sacerdote lazarista, que busca fortalecer o culto da Virgem de Luján, valorizando agentes que tiveram um papel-chave na promoção da devoçáo mariana. Foi o caso do rico devoto leigo don Juan de Lezica y Torrezuri, que em meados do século XVIII reconstruiu o templo da Virgem de Luján então em ruínas, e o cardeal Juan Mastai Ferreti, que em 1824 havia visitado o santuário argentino. Mais tarde, o mesmo cardeal sagrou-se como papa Pio IX, o mesmo que aprovou o dogma da Imaculada Conceição e que arquitetou a reação da Igreja à modernidade, no movimento conhecido como ultramontanismo.

Nos textos de Mariela G. Ceva e Silvina M. Olaechea estão presentes as tensóes entre, de um lado, o nacional e o estrangeiro e, de outro, o nacional e o regional. A primeira autora destaca as peregrinaçóes efetuadas pelos imigrantes italianos em Luján, no período da comemoração do centenário da independência argentina, em 1910. Mariela Ceva se preocupa primeiramente em contextualizar a ação que a Igreja Católica vinha 
desenvolvendo, desde aproximadamente 1870, no sentido de atrair e integrar aquele segmento da população por meio de rituais e atividades sociais. As peregrinações faziam parte, portanto, de um movimento mais amplo de inserçáo social e de evangelização. O santuário da Imaculada Concepção de Luján, para onde se destinavam aqueles imigrantes, há décadas já vinha acolhendo muitas levas de romeiros argentinos, sob o patrocínio de algumas autoridades civis e do clero, que buscavam conferir ao santuário uma projeção nacional. A inauguração da basílica de Luján em 1910, durante as comemoraçôes do centenário da independência, e a elevaçáo da Virgem de Luján à condição de padroeira da Argentina, do Uruguai e do Paraguai, em 1930, podem ser vistas como desdobramentos das iniciativas anteriores de promoção do culto mariano. Desfilando sob as bandeiras argentina e italiana, devotos provenientes de diferentes regiôes da Itália encontravam durante a peregrinação ao santuário oportunidades de reviverem antigas identidades, agora redefinidas pela condição comum de imigrantes. Tais romarias foram efetuadas até a década de 1940.

O texto de Silvina Olaechea, dedicado às peregrinaçóes de bolivianos e gaúchos em Luján, traz à luz questôes ligadas à afirmação de identidades nacionais e regionais. Os primeiros chegaram à Argentina a partir da década de 1950, para atuar principalmente como trabalhadores agrícolas. Cerca de trinta anos depois, as romarias de bolivianos a Luján foram organizadas pela açáo pastoral da Igreja. Ao colocar em prática diretrizes, que foram mais tarde sistematizadas no Do- cumento de Aparecida (2007), a instituição eclesiástica buscou promover a realização de romarias, vistas como instrumento de evangelização. A peregrinação anual dos bolivianos a Luján tem lugar no dia 5 de agosto, em que é venerada Nossa Senhora da Candelária de Copacabana, a padroeira da Bolívia. Na data assinalada, a imagem da Virgem de Copacabana vem ocupar um lugar de destaque no palco dos festejos principais defronte à basílica de Luján. $\mathrm{O}$ encontro das duas devoçóes marianas exibe novamente o caráter plástico do culto à Virgem, cuja multiplicidade de significados é proporcional à variedade de agentes sociais, etnias e grupos profissionais que atrai. O patrocínio da Virgem de Luján ao Movimento Tradicionalista Argentino é também sintomático a esse respeito. Desde a década de 1940, centenas e até milhares de peregrinos a cavalo, vestidos com a indumentária tradicionalmente associada a sua regiáo, são atraídos para o lugar de romaria em foco.

O estudo de Claudia F. Touris introduz os leitores na efervescente conjuntura política e religiosa do final da década de 1960 e princípios dos anos 1970. Sob o impulso das transformaçóes introduzidas pela Igreja Católica no Concílio Vaticano II, setores do clero argentino engajaram-se em açôes pastorais de caráter acentuadamente popular. A autora analisa de modo específico a atuação do Movimento de Sacerdotes para o Terceiro Mundo (MSTM). Fundado em 1967, o Movimento em questáo atuou nas periferias de centros urbanos, em especial, na regiáo metropolitana de Buenos Aires. Nesse espaço, os locais preferenciais de participação 
foram as villas, assentamentos populacionais caracterizados pela informalidade e pela precariedade das condiçóes de moradia. Sob a liderança de Carlos Mugica, os sacerdotes villeros denunciavam a instrumentalização do catolicismo por parte da elite e do episcopado tradicional, ao utilizarem a religiáo para sacralizar e legitimar relaçôes de poder. Em 1969, na primeira peregrinação organizada pelos sacerdotes villeros ao santuário de Luján, os folhetos distribuídos na romaria continham súplicas à Virgem por trabalho e salário justos para a população das villas.

Sob o ponto de vista teológico, o movimento do clero villero abraçava as diretrizes da Teologia do Povo ou Pastoral Popular, uma das correntes da Teologia da Libertaçáo. Considerava-se que as camadas populares eram portadoras de um catolicismo mais autêntico do que o das elites, devendo por isso ser qualificado como uma concreta encarnação do cristianismo. Carecia de legitimação considerar "evangelho degradado ou magia disfarçada" tal forma de religiosidade. Partindo desses pressupostos quase culturalistas, os sacerdotes villeros procuraram valorizar os rituais e as manifestaçóes sacramentais próprias do catolicismo popular. Ainda que procurassem despertar a conscientização dos fiéis em face das demandas cotidianas, o clero já referido não sobrevalorizou os aspectos sociopolíticos, como praticaram outras vertentes da Teologia da Libertação. Não obstante, no início dos anos 1970, o movimento villero experimentou uma crescente politizaçáo, aproximando-se do peronismo e dos montoneros.

O último artigo da coletânea, de autoria do geógrafo Fabián C. Flores, analisa a emergência do culto mariano na cidade de S. Nicolás, um porto fluvial localizado às margens do rio Paraná, a cerca de 240 quilômetros de Buenos Aires. No pós-guerra, e de modo acentuado a partir de 1960, com a inauguração oficial da siderúrgica Sociedad Mixta Siderúrgica Argentina (Somisa), a localidade de San Nicolás atraiu grande contingente de trabalhadores para atuar no setor de transformaçáo. O processo de industrialização foi capaz de redefinir a identidade local, pois San Nicolás passou a ser representada como a "cidade do aço". Uma parte da mão de obra se fixou no bairro operário da Somisa, no interior do qual os trabalhadores estabeleciam relaçôes de pertencimento coletivo à "comunidade do aço". Outra parte se estabeleceu em villas precárias nos subúrbios de San Nicolás. Nessas villas periféricas, predominavam trabalhadores provenientes das províncias do noroeste argentino, e inclusive do Paraguai.

A política de afastamento do Estado do setor de transformaçáo, que se esboçou ao longo da década de 1980, se intensificou em 1991, com a privatizaçáo da Somisa. Logo, na cidade de San Nicolás, se tornaram visíveis os efeitos da desindustrialização, sendo um dos mais evidentes a redução do contingente de trabalhadores, cujas vagas foram substituídas por precárias ocupaçóes no setor de serviços. Em 1983, em meio a tal processo, se verificaram as primeiras apariçóes da Virgem Maria em San Nicolás. Gladys Quiroga da Motta, uma mulher que vivia em uma das villas periféricas, considerava-se portadora de diversas mensagens enviadas pela Virgem, que lhe teria revelado inclusi- 
ve o local onde seria construído um novo santuário em sua homenagem. $\mathrm{O}$ apoio da municipalidade à cessão dos terrenos para a construção do templo e a atração exercida sobre a população local pelas apariçóes foram responsáveis, em duas décadas, por substantivas redefiniçôes das identidades locais. A antiga representação da "cidade do aço" cedeu aos poucos espaço para a emergência de uma nova imagem local, "a cidade de Maria”. O templo sob o patrocínio da Virgem do Rosário de San Nicolás tornou-se lugar de peregrinação, ocupando uma parte da população local na atividade do turismo religioso.

Um dos méritos trazidos pelo enfoque metodológico da história regional aplicado aos estudos mencionados diz respeito à superação da escala local para a observação dos processos em análise. Os estudos de santuários locais, sob o ponto de vista da pesquisa histórica ${ }^{1}$ ou antropológica ${ }^{2}$ priorizaram as trocas simbólicas estabelecidas entre os fiéis e as imagens sagradas. Isto é, a oferta de dons materiais e a realização de promessas por parte dos romeiros corresponderia à realização de milagres e intercessóes efetuadas pelos advogados celestes. Nesse tipo de análise, não se torna muito visível a operação de determinados grupos de interesses e de instituiçôes, que se apropriam do conteúdo simbólico das imagens e das apariçóes,

1 Ver, por exemplo, CHRISTIAN JR., William. Local religion in sixteenth century Spain. Princeton: Princeton University Press, 1981.

${ }^{2}$ Ver SANTALÓ, C. Álvarez; BUXÓ, Maria Jesús e BECERRA, S. Rodríguez (Coords.). La religiosidad popular: hermandades, romerías y santuarios. Madri: Anthopos, 1989. conferindo-lhes novos significados. Sob este ponto de vista, a coletânea aqui resenhada se aproxima do estudo de Carlos Alberto Steil, ${ }^{3}$ no qual a base local de observação leva em conta a ação da instituição eclesiástica que, dirigindo-se por objetivos mais universais, redefine e atribui novos significados ao catolicismo dos devotos da região.

Náo obstante, a obra coletiva aqui resenhada poderia ganhar mais fôlego aproximando-se de outras contribuiçôes historiográficas dirigidas à análise do culto mariano na ibero-américa, particularmente as obras de Jacques Lafaye e de David Brading. ${ }^{4}$ Ainda que náo estejam inseridas no campo da história regional, as duas obras mencionadas contemplam questóes que emergem nas análises acerca do santuário de Luján, em especial as identidades étnicas e o problema comum da identidade nacional. No que tange à América portuguesa e ao Brasil independente, os estudos acerca da devoção mariana se encontram ainda em patamar mais incipiente, apesar de Nossa Senhora da Conceição ter sido considerada, em 1640, padroeira do Reino de Portugal e, mais tarde, do Império brasileiro. Nesse sentido, os estudos reunidos na coletânea podem fornecer novos subsídios a comparaçóes entre diferentes formas de devoção mariana na ibero-américa. Em particular, as análises que Juliana Beatriz Almeida de Souza dedi-

\footnotetext{
${ }^{3}$ STEIL, Carlos Alberto. O sertão das romarias: um estudo antropológico sobre o santuário de Bom Jesus da Lapa - Bahia. Petrópolis: Vozes, 1996.

${ }^{4}$ LAFAYE, Jacques. Quetzalcóatl et Guadalupe. La formation de la conscience nationale au Mexique (1531-1813). Paris: Gallimard, 1974; BRADING, David. La virgen de Guadalupe. Imagen y tradición. México: Taurus, 2002.
} 
cou à Virgem da Conceição Aparecida, ${ }^{5}$ cuja imagem lembrava as características da Virgem de Guadalupe mexicana; assim como o estabelecimento de Nossa Senhora da Conceição Aparecida como padroeira do Brasil em 1931, segundo a análise de Rubem César Fernandes, ${ }^{6}$ praticamente na mesma época em que a Virgem de Luján recebera idêntica honraria em relação à Argentina, ao Uruguai e ao Paraguai.

* Doutor em história social pela Universidade de Sáo Paulo, professor adjunto da Universidade Federal do Rio de Janeiro. Rio de Janeiro, RJ, Brasil. E-mail: williamsmartins@uol.com.br.

\footnotetext{
${ }^{5}$ SOUZA, Juliana Beatriz de Almeida. Virgem mestiça: devoçáo à Nossa Senhora na colonização do Novo Mundo. Tempo: Revista do Departamento de História da UFF, Niterói, v. 6, n. 11, p. 77-92, jul. 2001. ${ }^{6}$ FERNANDES, Rubem César. Romarias da paixão. Rio de Janeiro: Rocco, 1994.
} 